\title{
Stem Modelling of Eucalyptus by Terrestrial Laser Scanning
}

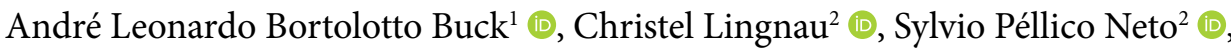 \\ Álvaro Muriel Lima Machado ${ }^{2}$ (D), Rorai Pereira Martins-Neto ${ }^{3}$ (1) \\ ${ }^{1}$ Sul Florestas Geo Engenharia (SFGEO), Lages, SC, Brasil \\ ${ }^{2}$ Universidade Federal do Paraná (UFPR), Curitiba, PR, Brasil \\ ${ }^{3}$ Universidade Estadual Paulista "Júlio de Mesquita Filho" (FCT/UNESP), Presidente Prudente, SP, Brasil
}

\begin{abstract}
The objective of this work was to obtain the stem volume from 3D-cloud points generated by terrestrial laser scanning in Eucalyptus stands. The processing started with using algorithms for tree detection in plantation (TDP) and stem filtering (Filter Dmax). Then, the acquisition of the total height was made semi-automatically and tridimensional modelling was performed through the adjustment of circumferences (AC) and the so-called triangulated irregular network (TIN). The results were compared with field data and conventional stem volume measurements. The detection accuracy was $100 \%$ for the trees in the plots while filtering reached $70 \%$ of the stem surface. The total height presented $\mathrm{R}^{2}=0.98$ and residuals less than $5 \%$. The estimated volumes, analyzed in sections with a length of $2 \mathrm{~m}$, were in average smaller than that obtained by the conventional Smalian method. The occlusion of points in the tree crown precluded obtaining the total stem volume.
\end{abstract}

Keywords: point cloud, three-dimensional modelling, stem volume. 


\section{INTRODUCTION AND OBJECTIVES}

Non-destructive methods of tree scaling constitute a relevant advance for forest measurements. They enable the obtention of stem volumes without felling the trees by using optical instruments, which facilitate faster data collection and reduction of field work (Kankare et al., 2013; Nicoletti et al., 2012).

The Terrestrial Laser Scanning (TLS) provides high precision measurements through a dense three-dimensional (3D) point cloud (Silva et al., 2013). This technology has been tested to collect data in forest stands by means of single scanning (a laser station) or multiple scanning (two or more stations). In the simple-sweep mode, data acquisition of the stems will be partial, whereas in the multiple-sweep procedure it is possible to obtain the total covering of the stems by 3D points, enabling the reconstitution of trees using three-dimensional modelling techniques (Aschoff et al., 2004).

Automatic processing of the point cloud is necessary to obtain the variables of interest because the $3 \mathrm{D}$ points are not qualified in terms of the object they represent. However, the geometric shapes provided by the points in the scan are important so that algorithms can be developed to indicate whether a certain set of points belongs to the tree stem, to the branches, to the leaves, or to another object in the field of view of the equipment.

The steps proposed in this work to accomplish automatic cloud processing of multiple scan points for stem modelling are: i) tree detection and log filtering; ii) find the total height; and iii) 3D modelling.

Detection of trees has been performed from geometric shapes. Cutting a cross section of the point cloud with different values of thickness between $0.1 \mathrm{~m}$ to $1 \mathrm{~m}$, allows the use of algorithms based on parameters of circumferences or cylinders that typically represent the shape of tree stems (Brolly \& Király, 2009; Buck et al., 2017; Schilling et al., 2011).

A reliable three-dimensional stem model will depend on the data available for modelling. Points that do not represent the surface of the stem should be eliminated by filtering. Automatic filtering methods seek to isolate stems based on concepts like threshold distance between neighboring points, intensity value or density of points along the stem (Simon et al., 2003).
The total height of a tree can be obtained from the difference between the points at the base of the stem and the apex of the crown (Aschoff et al., 2004; Hopkinson et al., 2004; Silva et al., 2013). However, the absence of points representing the apex of a tree is pointed out as the reason for occurrence of total height underestimation (Hopkinson et al., 2004; Martins Neto et al., 2013).

Fitting circumferences along transverse sections of the stem cloud points can be performed employing the least squares method. Moreover, the diameters obtained in this fitting are used for indirect determination of the trunk volume (Ascherff et al., 2004; Brolly \& Király, 2009).

A detailed stem model can be achieved when applying the triangulated irregular network (TIN) directly over the trunk surface data (Aschoff et al., 2004). The absence of points for modelling the stem in the crown region indicates a limitation for the application of this method.

After such considerations, the present study introduces an evaluation of the automation for 3D reconstruction of logs and the calculation of volume from terrestrial laser scanning in clonal plantations of Eucalyptus urograndis (hybrid of E. urophylla $\times$ E. grandis). The obtained results are compared with conventional tree scaling data.

\section{MATERIALS AND METHODS}

\subsection{Area of study and Terrestrial Laser Scanning (TLS)}

The study area is located in the municipality of Três Lagoas, Mato Grosso do Sul (MS), in a 5-year-old clonal plantation of Eucalyptus urograndis (hybrid of E. urophylla $\times$ E. grandis). The trees are planted with a spacing of $3.60 \mathrm{~m} \times 2.20 \mathrm{~m}$, which is equivalent to a density of 1,262 trees $\cdot \mathrm{ha}^{-1}$. The understory is characterized by the presence of undergrowth (grasses) and small isolated bushes. The relief is flat to smooth corrugation, with the average slope observed in the plot area being approximately $6 \%$.

Scans were performed using the Trimble TX5 equipment. The scanning resolution was fixed at $6 \mathrm{~mm}$ for a distance of $10 \mathrm{~m}$, and the acquisition rate was 122,000 points.second ${ }^{-1}$. Spherical targets, $145 \mathrm{~mm}$ in 
diameter and white in color, were positioned on tripods to assist the scans registration step. We adopted as a requirement that at least three targets were observed in each scan station.

Multiple scans were performed in circular plots of $400 \mathrm{~m}^{2}$ to achieve total stem cover. A reference station was installed at the center of the plot, where the reach of sight was $360^{\circ}$ horizontal $\times 300^{\circ}$ vertical with photographic records. There were also four stations located outside the perimeter of the plot with a reach of sight of $110^{\circ}$ horizontal $\times 300^{\circ}$ vertical (Figure 1).

The multiple scans were submitted to the registration procedure, since each sweep adopts a local reference system. The cloud point registration is based on the Helmert transformation with three transitions and three rotations (Equation 1). The cloud registration requires at least three tie points, that is, three targets (Wezyk, 2012) for the Helmert transformation to be applied (Bienert \& Maas, 2009; Martins Neto et al., 2015). The result of this step is a point cloud fused per plot in such a way that the admissible error for the union was less than $0.01 \mathrm{~m}$.
$\left[\begin{array}{l}\bar{X} \\ \bar{Y} \\ \bar{Z}\end{array}\right]=\left[\begin{array}{l}X_{0} \\ Y_{0} \\ Z_{0}\end{array}\right]+m R\left[\begin{array}{l}\overline{X_{n}} \\ \overline{Y_{n}} \\ \overline{Z_{n}}\end{array}\right]$

$\bar{X}, \bar{Y}, \bar{Z}$ : final vector; $X_{0}, Y_{0}, Z_{0}$ : translation vectors $(\mathrm{m}) ; m$ :fixed scaling factor provided by laser scan (equal to 1 ); $R$ : rotation matrix (radians); $\bar{X}_{n}, \bar{Y}_{n}, \bar{Z}_{n}$ : initial vector.

\subsection{Point cloud processing}

The proposed steps for point cloud processing of terrestrial laser scanning and for the algorithms employed to obtain the individual trunk volumes are presented in Figure 2.

The plot trees were detected through the implementation of the so-called Tree Detection in Plantation (TDP) algorithm (Buck et al., 2017). A cross section of the point cloud was extracted to reconstruct the spatial distribution of the trees in the stands. The interval established for this section was $1 \mathrm{~m}$, being $0.50 \mathrm{~m}$ above and below the origin $(Z=0)$ with respect to the reference (central) coordinate system.

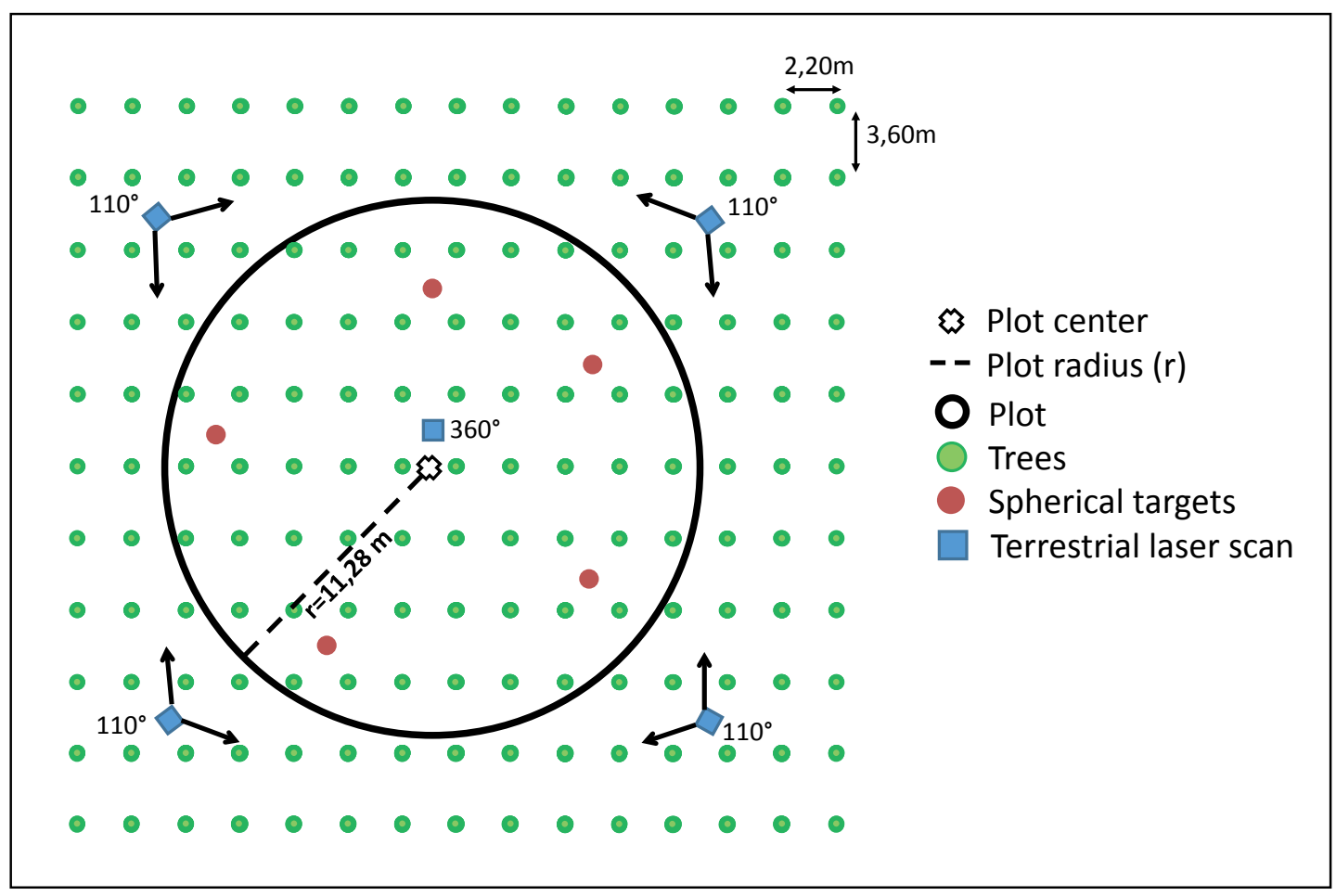

Figure 1. TLS stations and spherical targets configuration in a circular plot. 


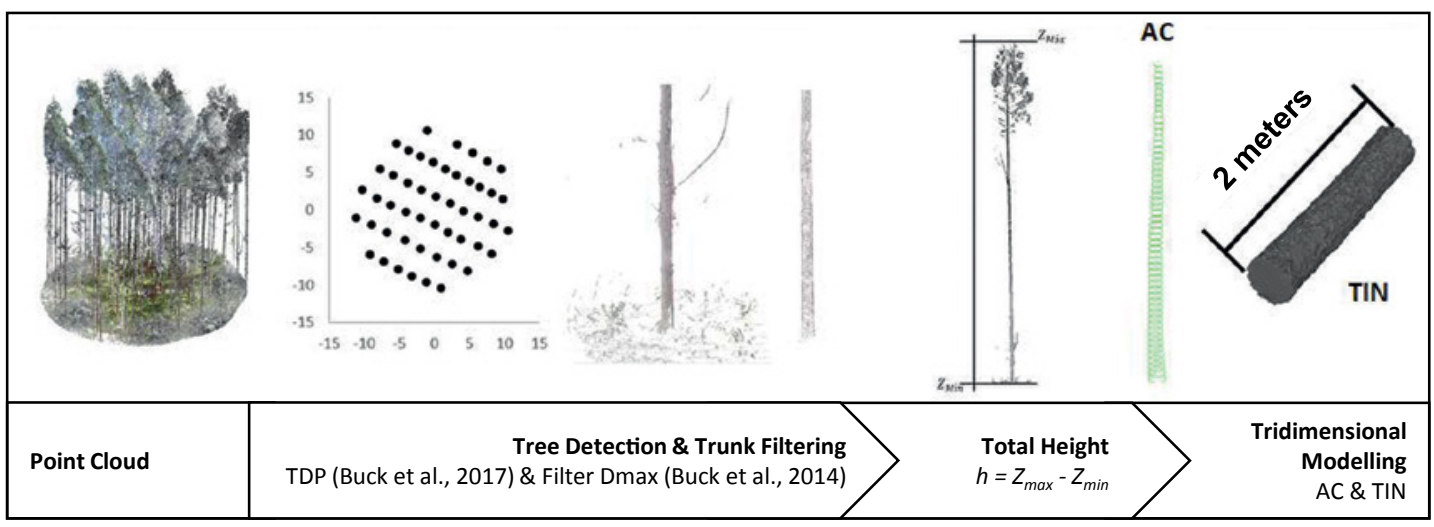

Figure 2. Steps to obtain trunk volume. h: height; $\mathrm{Z}_{\max }$ : highest point of the tree cloud; $\mathrm{Z}_{\min }$ : lowest point of the tree cloud; AC: adjustment of circumferences; TIN: triangulated irregular network.

The algorithm detects plot trees based on parameters of the terrestrial laser scanning, spacing and planting alignment. For each detected tree, the planimetric coordinates that define its location in the local coordinate system were assigned. From these coordinates, the tree was isolated within the point cloud using a radius of $1.80 \mathrm{~m}$ for the clipping. The radius corresponds to half the largest spacing defined in the alignment $(3.60 \mathrm{~m})$.

After tree detection, filtering was applied with the objective of making the stem surface data available for generation of a 3D model. The algorithm "Filter Dmax" (Buck et al., 2014) was applied specifically for stem isolation. Filtering is performed iteratively and in sections of the point cloud where a search radius is set by fitting a circle to the points in the section. The closest selection of points to the radius of the stem circumference represents the stem of the tree.

The algorithm was adapted to initiate the filtering from the origin of the local coordinate system, established at the height at which the equipment was installed in the field for the central scan $\left(X_{0}, Y_{0}, Z_{0}=0\right)$. In this way, the filtering occurs in two directions, namely ascending and descending. In the upward direction, the algorithm traverses the sections that represent the surface of the stem to the point of maximum vertical dimension of the point cloud $\left(\mathrm{Z}_{\max }\right)$. In the downward direction, the algorithm runs through all sections until it reaches points on the terrain surface, which defines the boundary dimension of the trunk $\left(\mathrm{Z}_{\min }\right)$.

The total height was determined from the difference between the maximum $\left(\mathrm{Z}_{\max }\right)$ and minimum $\left(\mathrm{Z}_{\min }\right)$ coordinates on the " $Z$ " axis of the point cloud of a tree
(Martins Neto et al., 2013; Silva, 2011). The maximum tree dimensions, represented by the top of the crown, were obtained semi-automatically through point cloud selection and editing tools.

Stem volume modelling was performed using two methods: i) Adjustment of circumferences along the stem (AC); and ii) triangulated irregular network (TIN). For the purposes of comparison with the conventional field-based tree scaling, we decided to perform modelling on logs of $2 \mathrm{~m}$ in length (Figure 3 ).

The successive fitting of circumferences to find diameters throughout the stem was performed using the least squares method. This fitting aimed at minimizing the variance or standard deviation of the Euclidean distances relative to the center of a crosssection of the tree stem (Ascherff et al., 2004; Bienert, 2013; Bienert et al., 2006; Brolly \& Király, 2009; Buck, 2011). The average of the resulting Euclidean distances corresponds to the radius of the fitted circumference, thereby providing the diameter.

The circumference fitting process was applied every $10 \mathrm{~cm}$ along the stem. The volumes were obtained by applying the Smalian formula in sections of $10 \mathrm{~cm}$ in length, whose sum of the small components represents the volume of each log, called Smalian (AC). The data were grouped in sections of $2 \mathrm{~m}$ in length, matching the size of the logs measured in the field. Thus, for each 2-m-log, whose extremities were measured in the field with a caliper (base and top of the log), 20 circumferences were used along its length.

The 3D model of logs composing the tree stem was also generated by applying the methodology proposed 


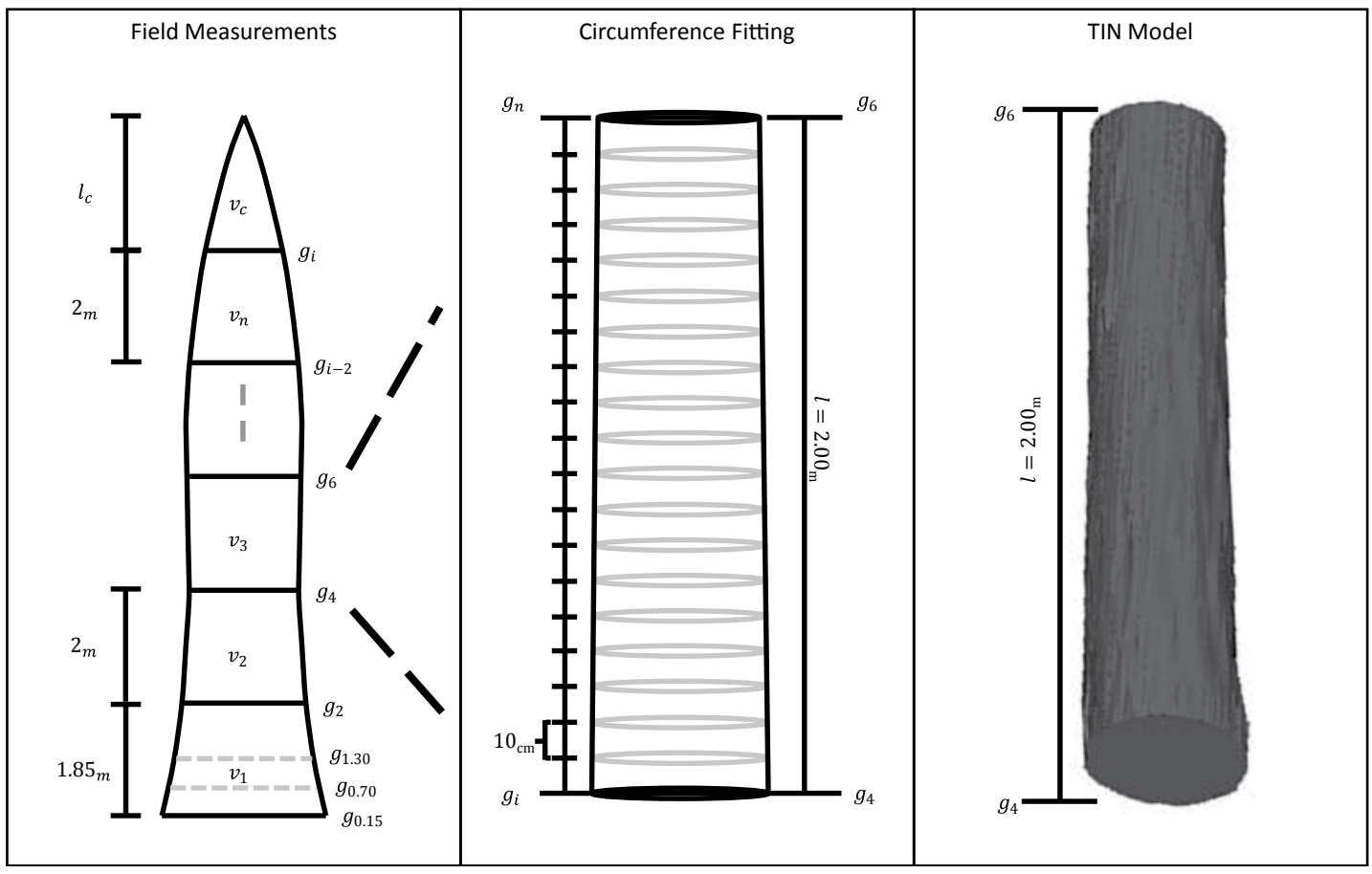

Figure 3. Stem modelling in logs of 2 meters. lc: cone length; vc: cone volume; vn: $n$-th section; g: cross section area; 1: log length.

by Aschoff et al. (2004), which describes the use of a triangulated irregular network (TIN) to render an accurate model of the tree stem.

\subsection{Comparison between conventional measurements and Terrestrial Laser Scanning (TLS)}

Data for this comparison were obtained in the four circular plots of $400 \mathrm{~m}^{2}$ raised by terrestrial laser scanning. The evaluation of results was performed for each stage of the processing.

The Detection and Filtering step was assessed in terms of efficiency of the algorithm for tree detection in the plot in relation to the count of trees in the field, as well as in terms of the percentage reached by stem filtering in relation to the total height of the trees. The total height was evaluated by means of linear regression between the heights obtained with the field tree scaling measurement (parametric value) and the heights rendered by laser data processing.

The volumes obtained in the modelling of the stem with laser data by the AC and TIN methods were compared with the conventional procedure using a caliper to provide volumes of 41 trees selected and felled in the plots and dispersed over the diametric classes.

We selected the Smalian's method because it was adopted in the forest inventory of the company where the study was carried out.

\section{RESULTS AND DISCUSSION}

\subsection{Detection and filtering}

The application of the TDP algorithm resulted in the detection of $100 \%$ of the trees in the plots. The results can be attributed primarily to the use of multiple scans that have minimized the shading effect, to the alignment/spacing of the planting, and to the occurrence of natural fall of branches. This percentage is higher than those reported in the literature.

Simonse et al. (2003), when in Douglas-fir forests in Germany, found correspondence of about $90 \%$ of the individuals. Bienert et al. (2007), when in coniferous forests (Picea abies) and deciduous trees (Fagus sylvatica), identified about $97 \%$ of the trees automatically in the 
processing of the point cloud, both with detection methodology based on the tendency of the stem to form circumferences. Undetected trees were covered by small branches or shaded by other trees.

Liang \& Hyypä (2013), Mengesha et al. (2015), and Martins Neto (2016) automatically detected 95.7\%, $86.2 \%$ and $96.2 \%$, respectively. In these studies, the forests did not present an alignment, which gave rise to the shading/occlusion of the trees in the sweep.

From the coordinates of each detected tree, it was possible to isolate and identify the demarcated trees in the field for scaling. The radius for the cut established at $1.80 \mathrm{~m}$ was adequate for the isolation of cloud points from each tree for filtering.

The "Filter Dmax" algorithm enabled the filtering of isolated trees that averaged from $28.1 \mathrm{~m}$ to about $70 \%$ of the total height. Filtering was not efficient below the commercial height of wood utilization $(6 \mathrm{~cm}$ in diameter) due to the high density of the canopy. The average commercial height was $22.7 \mathrm{~m}$ versus $19.4 \mathrm{~m}$ for the stem filtering height. The algorithm was developed for application in multiple sweeps, where a priori the stem is totally covered by points and, therefore, the low density of laser points in the upper parts of the trees can be pointed out as the factor that influences negatively on filtering.

In an isolated tree of Pinus spp., Buck et al. (2014), using the same "Filter Dmax", obtained $72 \%$ of the filtered stem, corroborating the aforementioned results. Buck et al. (2014), Mengesha et al. (2015), and Martins Neto (2016) reported limitations of filtering in the upper portions of the trunk due to the presence of leaves and branches that preclude the measurement of points on the surface of the stem. In these studies, filtering was efficient below the beginning of the tree crowns.

\subsection{Total tree height}

Data processing by calculating the difference of the $\mathrm{Z}_{\max }$ and $\mathrm{Z}_{\text {min }}$ dimensions resulted in precise estimates of the total height, reaching a coefficient of determination equal to 0.98 . The predominance of positive residues indicates underestimation of the total height variable, which was influenced by the absence of points at the apex of the tree crown (Figure 4).

The underestimation of total height has been reported by several authors who used TLS to determine this variable. This is attributed to the absence of points at the apex of the tree due to the high density of needles at the base of the crown and to the positioning of the laser in relation to the total height of the tree (Martins Neto et al., 2013).

Applying visual interpretation of the point cloud related to the isolated trees, it was possible to verify that the underestimates are directly related to the absence of points at the apex of the tree crowns provided by TLS. It was also possible to verify that the $\mathrm{Z}_{\text {max }}$ quota in a semi-automatic way corroborated the results, eliminating the possibility that adjacent tree crown points were automatically determined as the $\mathrm{Z}_{\max }$ dimension of the tree.

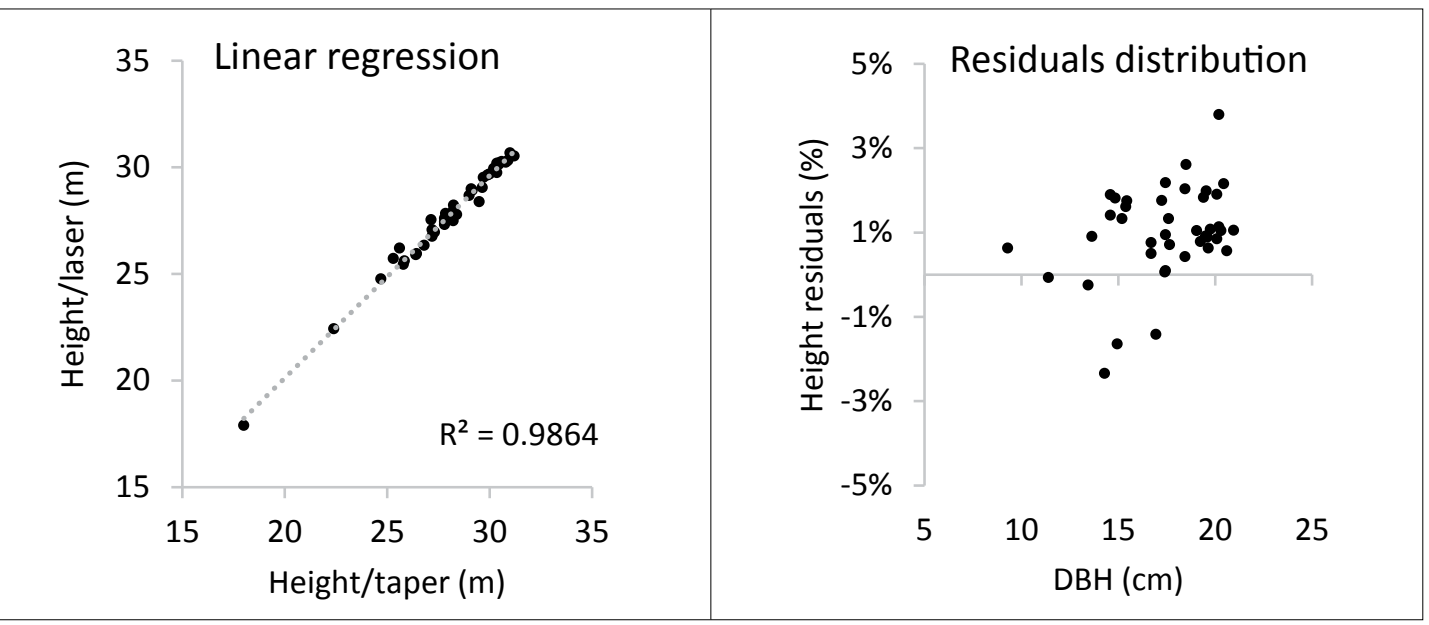

Figure 4. Results for total height. 


\subsection{Volumes obtained by terrestrial laser data processing and conventional scaling}

The reconstruction of the stems by the models that employed laser data was achieved up to approximately $18 \mathrm{~m}$, which corresponds to nine logs modeled in segments of $2 \mathrm{~m}$ in length. Note that there is a difference in such volumes in relation to those obtained by the conventional Smalian method (CALIPER), since the methods that use laser data for volume modelling present smaller values for this variable in all modeled logs (Figure 5A-B).

The TIN model resulted in the lowest estimate from the laser data and, therefore, the largest difference from those obtained by the conventional method. The average percentage differences were less than $20 \%$ up to $12 \mathrm{~m}$ in height and up to $36 \%$ for $18 \mathrm{~m}$ in height (Figure 5B).

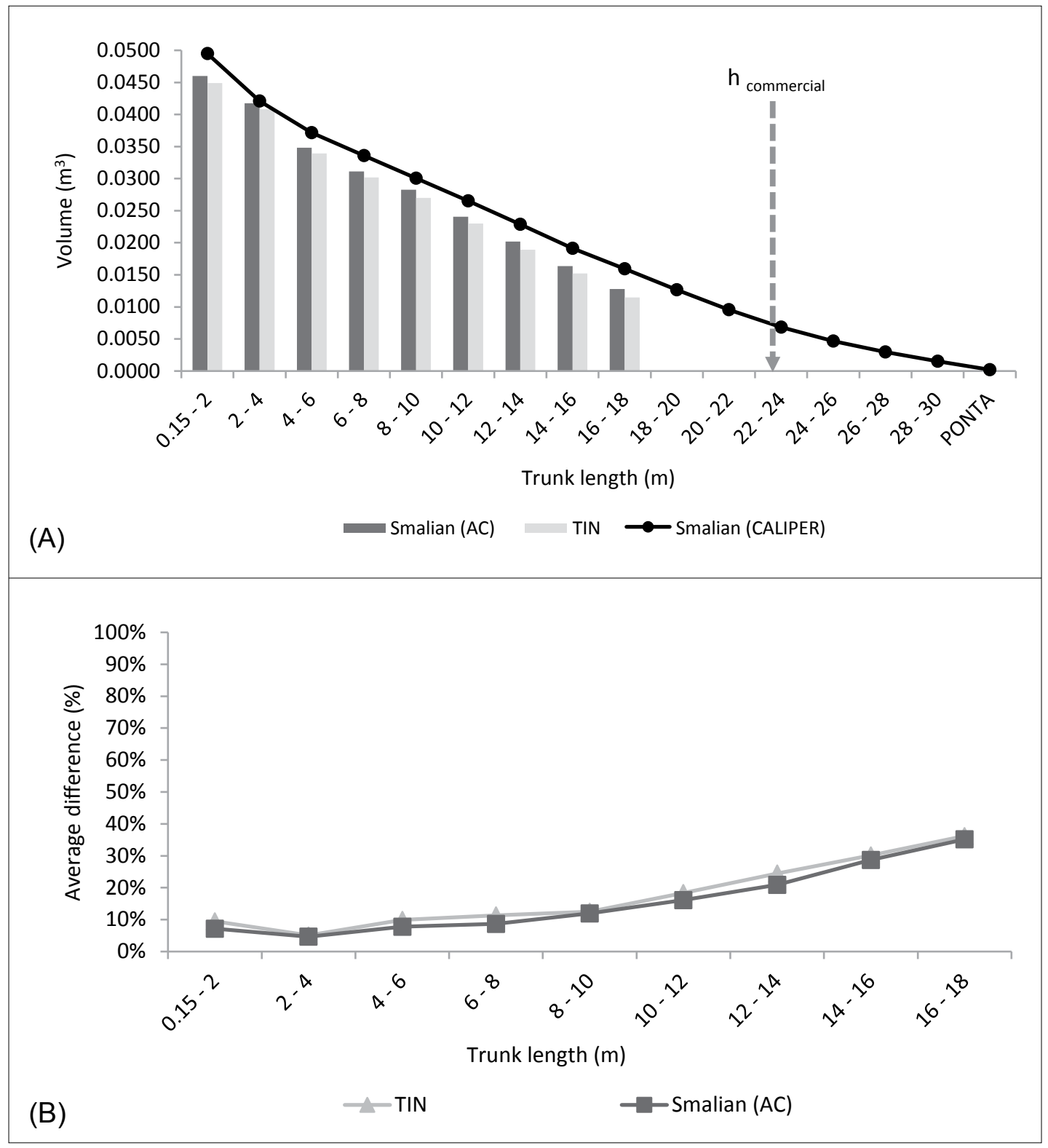

Figure 5. (A) log volume; (B) average difference compared to Smalian (CALIPER). h: height; AC: adjustment of circumferences; TIN: triangulated irregular network. 


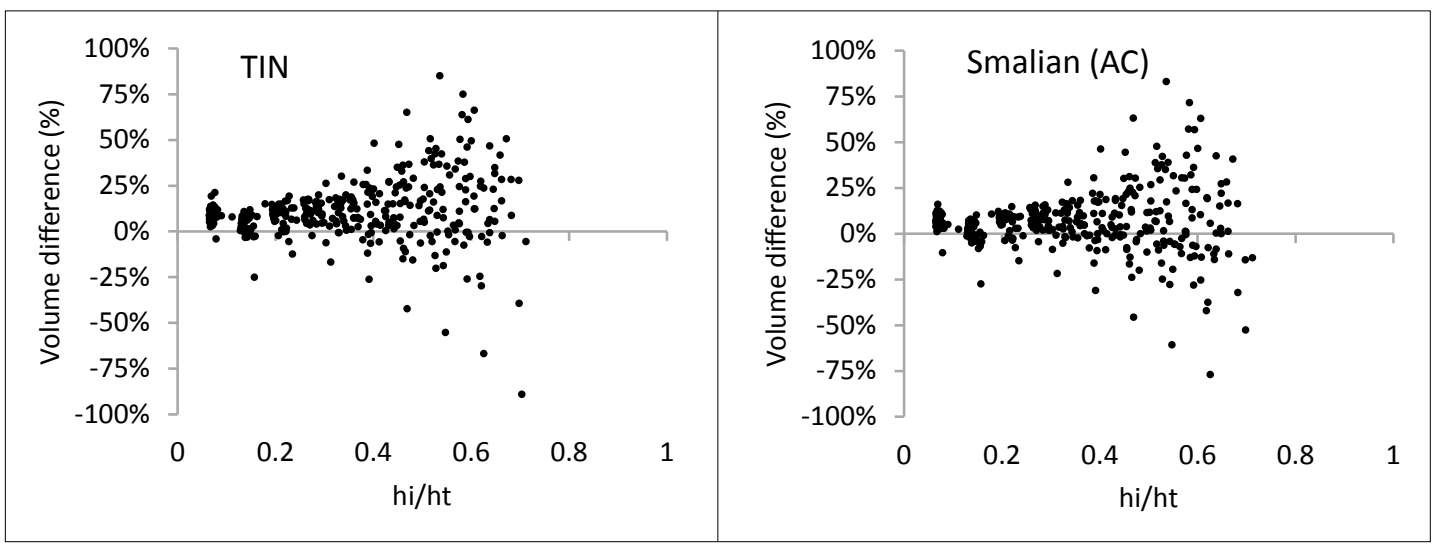

Figure 6. Distribution of volume differences for relative height. TIN: triangulated irregular network; AC: adjustment of circumferences; hi: i-th height; ht: total height.

The graphs of distribution of differences in relation to the conventional volume obtained by the Smalian method (CALIPER) indicate the magnitude of the differences as a function of total height (Figure 6).

The difference found for the volume as a function of the tree's total height is larger as the logs approach the apex of the tree crown. It is observed that the differences found up to the third log are constant for the two proposed methods, within a range of $-25 \%$ to $25 \%$. It is possible to graphically verify that the magnitude of the positive differences is predominant. This indicates a greater number of underestimates compared to the conventional method.

Murphy (2008) used cylinder fitting along the stem to determine the volume of trees in plots of Douglas Fir. This author underestimated 22\%, pointing out the difficulty of automating the processes to obtain the volume of the under-forest, tree density in the plot and tree architectures. After manual refinement, the underestimates decreased to $7 \%$. Saarinen et al. (2017) estimated the volume of trees in a native forest of Finland fitting diameters of $5 \mathrm{~cm}$ along the stem. They then applied the Huber method. The volumes were underestimated between $12.4 \%$ and $6.8 \%$ when compared to the conventional scaling. The authors pointed out that the diameters estimated by the processing of the cloud composed of laser points represent better the shape of the stem than the conventional measurements carried out with a caliper or a tape.

It is worth mentioning that conventional scaling methods, such as the Smalian, do not consider the real stem geometry, but rather an approximation using solids of revolution approximating the shape of the trees (Machado \& Figueiredo Filho, 2006). Considering the natural irregularities in stem geometry, the TIN model can be identified as the method that best represents the stem shape, approximating the parametric value of the volume obtained by the water displacement method using an instrument called Xylometer.

Buck (2011) compared the volumes obtained by 3D modelling using TIN and rigorous scaling methods with the parametric value of the volume provided by the Xylometer. The results showed that 3D modelling came closer to the parametric value than by using the conventional tree scaling. Errors below 1\% for the first tree logs were reported. Therefore, the Smalian method (CALIPER), used as truth field and parameter for comparison, possibly overestimates the volume of the first logs.

\section{CONCLUSIONS}

The use of terrestrial laser scanning for trunk modelling represents an advance in data collection as it is an alternative to destructive tree scaling methods. The automation of the steps necessary for modelling can be considered essential to the potential use of the information obtained from the point cloud generated by this technology.

The set of steps proposed in this study to automate the 3D modelling allowed partial modelling of stem volume. The absence of points in the crown region 
prevented the total volume from being obtained, so regression methods need to be applied to estimate the volume of the upper trunk sections.

Laser scan data allow reliable reconstruction of tree stem geometry as long as its surface is covered by points. Further studies should be performed to compare automated volumetric modelling with parametric volume data in order to verify the significance of the results and validate the methodology.

\section{ACKNOWLEDGEMENTS}

The authors thank the Eldorado do Brasil company for the support in the research project and for the areas and team being available for helping collecting data, as well as Santiago \& Cintra, for providing equipment and technical support for collecting data in the field. We also thank the Graduate Program in Forest Engineering at Universidade Federal do Paraná (UFPR) and the Coordination for the Improvement of Higher Education Personnel (Capes).

\section{SUBMISSION STATUS}

Received: 23 Mar., 2016

Accepted: 14 Ago., 2018

\section{CORRESPONDENCE TO}

\section{André Leonardo Bortolotto Buck}

Universidade Federal do Paraná (UFPR),

Av. Prefeito Lothário Meissner, 632,

CEP 80210-170, Curitiba, PR, Brazil

e-mail: andrebuck.sf@gmail.com

\section{REFERENCES}

Aschoff T, Thies M, Spiecker H. Describing forest stands using terrestrial laser scanning. International Archives of Photogrammetry, Remote Sensing and Spatial Information Sciences 2004 [cited 2019 May 16]; 35(5): 237-241. Available from: http://bit.ly/2JDWycK

Bienert A. Automatische Extraktion von 3D: Baumparametern aus terrestrischen Laserscannerdaten [dissertação]. Dresden: Fakultät Umweltwissenschaften, Technischen Universität Dresden; 2013.

Bienert A, Maas HG. Methods for the automatic geometric registration of terrestrial laser scanner point clouds in forest stands. In: Proceedings of the ISPRS Workshop on
Laser Scanning; 2009 Sept 1-2; Paris, France. Lemmer: Société Française de Photogrammétrie et de Télédétection; 2009. p. 93-98

Bienert A, Scheller S, Keane E, Mohan F, Nugent C. Tree detection and diameter estimations by analysis of forest terrestrial laser scanner point clouds. In: Proceedings of the ISPRS Workshop on Laser Scanning; 2007 Sept 1214; Espoo, Finland. Hannover: International Society for Photogrammetry and Remote Sensing; 2007. p. 50-55.

Bienert A, Scheller S, Keane E, Mullooly G, Mohan F. Application of terrestrial laser scanners for the determination of forest inventory parameters. International Archives of Photogrammetry, Remote Sensing, and Spatial Information Sciences 2006 [cited 2019 May 16]; 36(5): 1-5. Available from: http://bit.ly/2JHVnJt

Brolly G, Király G. Algorithms for stem mapping by means of terrestrial laser scanning. Acta Silvatica et Lignaria Hungarica 2009 [cited 2019 May 16]; 5(1): 119-130. Available from: http://bit.ly/2HlkArp

Buck ALB. Análise de métodos de filtragem em dados laser scanner terrestre aplicados à modelagem tridimensional do tronco de Pinus spp. [dissertação]. Curitiba: Setor de Ciências Agrárias, Universidade Federal do Paraná; 2011.

Buck ALB, Lingnau C, Machado AML, Péllico Netto S. Detecção de árvores em nuvens de pontos de varredura laser terrestre. Boletim de Ciências Geodésicas 2017; 23(1): 21-38. 10.1590/S1982-21702017000100002

Buck ALB, Silva MN, Lingnau C, Machado AML, Neto RPM. Um algoritmo para filtragem do tronco em nuvem de pontos laser terrestre de árvores de Pinus spp. Boletim de Ciências Geodésicas 2014; 20(4): 806-829. 10.1590/ S1982-21702014000400046

Hopkinson L, Chasmer L, Young-Pow C, Treitz P. Assessing forest metrics with a ground-based scanning lidar. Canadian Journal of Forest Research 2004; 34(3): 573-583. 10.1139/x03-225

Kankare V, Holopainen M, Vastaranta M, Puttonen E, Yu X, Hyyppä J et al. Individual tree biomass estimation using terrestrial laser scanning. ISPRS Journal of Photogrammetry and Remote Sensing 2013; 75(1): 6475. 10.1016/j.isprsjprs.2012.10.003

Liang X, Hyyppä J. Automatic stem mapping by merging several terrestrial laser scans at the feature and decision levels. Sensors 2013; 13(2): 1614-1634. 10.3390/s130201614

Liang X, Litkey P, Hyyppä J, Kukko A, Kaartinen H, Holopainen M. Plot-level trunk detection and reconstruction using one-scan-mode terrestrial laser scanning data. In: Proceedings of the 1stInternational Workshop on Earth Observation and Remote Sensing Applications; 2008 June 30-July 1; Beijing, China. Piscataway: IEEE Xplore Digital Library; 2008. p. 1-5.

Litkey P, Liang X, Kaartinen H, Hyyppä J, Kukko A, Holopainen M. Single-scan TLS methods for forest 
parameter retrieval. In: Hill R, Rosette J, Suárez J, editors. Proceedings of the 8th SilviLaser; 2008 Sept 1719; Edinburg, Scotland, United Kingdom. Bournemouth: SilviLaser 2008 Organizing Committee; 2008. p. 295-304.

Machado SA, Figueiredo Filho A. Dendrometria. Guarapuava: Editora Unicentro; 2006.

Martins Neto RP. Extração de variáveis dendrométricas em árvores de Pinus taeda L. a partir de dados TLS e ALS [dissertação]. Lages: Centro de Ciências Agroveterinárias, Universidade do Estado de Santa Catarina; 2016.

Martins Neto RP, Buck ALB, Silva MN, Lingnau C, Machado AML, Pesck VA. Avaliação da varredura laser terrestre em diferentes distâncias da árvore para mensurar variáveis dendrométricas. Boletim de Ciências Geodésicas 2013; 19(3): 420-433. 10.1590/S1982-21702013000300005

Martins Neto RP, Conto T, Buck ALB, Lingnau C, Pesck VA, Zanon MLB. Proposta de um algoritmo para extração semiautomática do fuste em dados de varredura laser terrestre e determinação do volume comercial. In: Schneider PR, Finger CAG, Fleig FD, Farias JA, editors. Anais do 60 Simpósio Latino-Americano sobre Manejo Florestal; 2015 Sept 22-24; Santa Maria, Rio Grande do Sul, Brasil. Santa Maria: Universidade Federal de Santa Maria; 2015. v. 6. p. 473-478.

Mengesha T, Hawkins M, Nieuwenhuis M. Validation of terrestrial laser scanning data using conventional forest inventory methods. European Journal of Forest Research 2015; 134(2): 211-222. 10.1007/s10342-014-0844-0

Murphy G. Determining stand value and log product yields using terrestrial Lidar and optimal bucking: a case study. Journal of Forestry 2008; 106(6): 317-324. 10.1093/ jof/106.6.317

Nicoletti MF, Carvalho SPCE, Batista JLF. Revisão bibliográfica sobre métodos não-destrutivos de cubagem de árvores em pé visando à determinação da biomassa.
Revista Científica Eletrônica de Engenharia Florestal 2012 [cited 2019 May 16]; 20(1): 102-116. Available from: http://bit.ly/2Yx4W1Q

Saarinen N, Kankare V, Vastaranta M, Luoma V, Pyörälä J, Tanhuanpää T et al. Feasibility of Terrestrial laser scanning for collecting stem volume information from single trees. ISPRS Journal of Photogrammetry and Remote Sensing 2017; 123: 140-158. 10.1016/j.isprsjprs.2016.11.012

Schilling A, Schmidt A, Maas HG. Automatic tree detection and diameter estimation in terrestrial laser scanner point clouds. In: Wendel A, Sternig S, Godec M, editors. Proceedings of the 16th Computer Vision Winter Workshop; 2011 Feb 2-4; Mitterberg, Austria. Graz: Verlag der Technischen Universität Graz; 2011. p. 75-83. 10.3217/978-3-85125-141-8

Silva MN. Aplicação de laser scanner terrestre para determinação de variáveis dendrométricas em Pinus spp. [dissertação]. Curitiba: Setor de Ciências Agrárias, Universidade Federal do Paraná; 2011.

Silva MN, Buck ALB, Lingnau C, Machado AML, Martins Neto RP, Pesck VA. Laser scanner terrestre para medições florestais: princípios e aplicações. Revista Brasileira de Cartografia 2013 [cited 2019 May 16]; 65(6): 1143-1152. Available from: http://bit.ly/2YAVcE9

Simonse M, Aschoff T, Spiecker H, Thies M. Automatic determination of forest inventory parameters using terrestrial laser scanning. In: Hyyppä J, Naesset E, Olsson $\mathrm{H}$, Granqvist Phalén T, Reese H, editors. Proceedings of the ScandLaser Scientific Workshop on Airborne Laser Scanning of Forests; 2003 Sept 3-4; Umeå, Sweden. Umeå: Sveriges Lantbruksuniversitet; 2003. p. 252-258.

Wezyk P. The integration of the terrestrial and airborne laser scanning technologies in the semi-automated process of retrieving selected trees and forest stand parameters. Ambiência 2012; 8(4): 531-546. 10.5777/ ambiencia.2012.04.08 